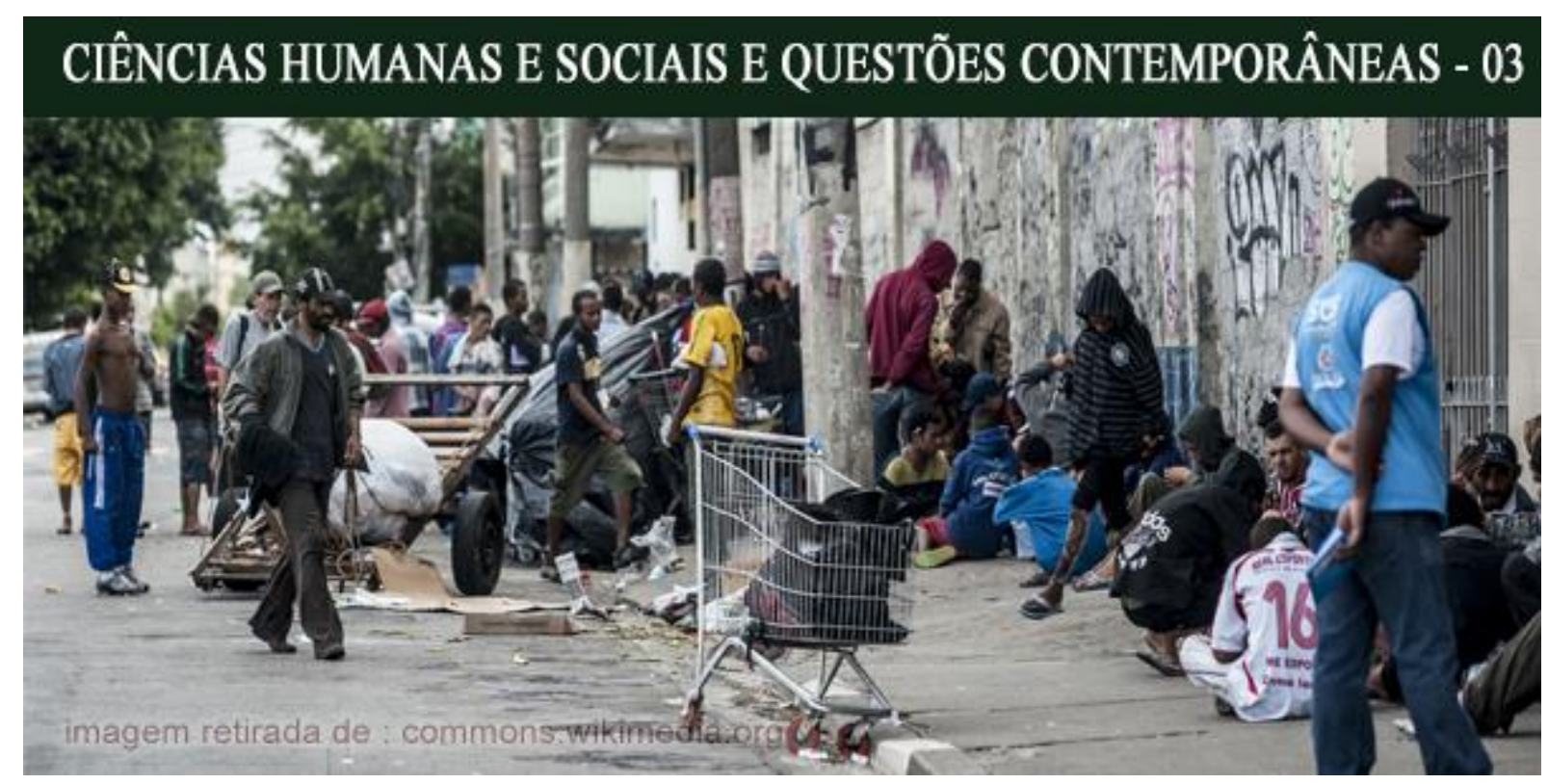

\title{
CLÍNICA PSICANALÍTICA E SEGREGAÇÃO EM DISPOSITIVO DE INTERNAÇÃO PARA USUÁRIOS DE ÁLCOOL E OUTRAS DROGAS
}

\author{
Maycon Rodrigo da Silveira Torres \\ ORCID: https://orcid.org/0000-0001-9479-7521. \\ E-mail:maydrigo@hotmail.com. \\ Paulo Eduardo Viana Vidal \\ ORCID: https://orcid.org/0000-0001-7897-6933.
}

Resumo: O presente artigo tem por objetivo discutir a tese de que o modelo de tratamento de usuários de drogas em regime de internação funciona como dispositivo de segregação. O percurso metodológico partiu da elaboração de casos clínicos de pacientes internados em enfermaria especializada de um hospital psiquiátrico, identificando uma relação de continuidade lógica entre as cenas de uso de drogas e a internação. A análise dos dados foi realizada com o aporte teórico da psicanálise de orientação lacaniana. De acordo com a teoria lacaniana dos discursos, os problemas associados ao uso de substâncias psicoativas, ou toxicomanias, são efeitos da relação entre o desenvolvimento do discurso científico e o avanço do capitalismo, na medida em que a ciência opera no real através de seu trabalho de formalização matemática e introduz no mercado novos objetos de consumo como as drogas. Enquanto o Discurso do Mestre induz a perda do objeto de gozo pela incidência da linguagem e produz um sujeito dividido, o Discurso do Capitalista se articula com a homogeneização do gozo operada pela ciência e aumenta o risco de abolição da subjetividade. Como efeito, o laço social que atravessa estes discursos é a segregação, expressa em diferentes formas de privação de liberdade. A prática psicanalítica sustenta o lugar do sujeito como resistência ao comando do mestre, impondo limites ao movimento institucional de suprimir a experiência subjetiva em nome de uma cura generalizada.

Palavras-chave: Toxicomanias. Segregação. Psicanálise. Discurso do Mestre. Discurso do Capitalista.

\section{PSYCHOANALYSIS AND SEGREGATION OF ALCOHOL AND DRUG USERS' HOSPITALIZATION}

Abstract: This paper discusses a thesis on drug addict treatment as a segregation device. Its methods is based on clinical cases of patients admitted in specialized ward at psychiatric Hospital. It was identified association between hospitalization and places of drug intake as a logical continuity. Data was analyzed using Lacanian oriented psychoanalysis. Drug addiction is related to the development of the scientific discourse as science produces real

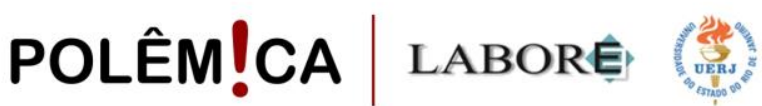

Polêmica - Revista Eletrônica da Uerj - Rua São Francisco Xavier, 524, $1^{\circ}$ andar bloco D, sl.1001 • Tels.: +55 21 2334-4088 / 4087 • http://www.e-publicacoes.uerj.br/index.php/polemica/index http://www.labore.uerj.br • laboreuerj@yahoo.com.br 
from its work by mathematical formalization as capitalism expands and introduces new consumer goods. As Master Discourse induces a loss of jouissence object by incidence of language and produces a splitted subject, Capitalist Discourse is articulated to the homogenization of juissence made by science and increases risk of abolishing subjectivity. In consequence, segregation is the social bond that crosses these discourses and it is expressed by different means of freedom privation. Psychoanalytical treatment for drug addicts sustains a place for subject as resistence to mater's command. It imposes a limit to institutional tendance to supress subjectivity for a generalized cure.

Keywords: Drug addiction. Segregation. Psychoanalysis. Master Discourse. Capitalist Discourse.

\section{Introdução}

A inclusão do uso problemático de álcool e outras drogas nas políticas públicas em Saúde Mental nos últimos anos é reflexo de tensionamento de forças na abordagem desta questão. Ao longo do século XX, o modelo de tratamento padrão de usuários de drogas foi baseado no aspecto repressivo das substâncias psicoativas, tanto no campo jurídico quanto de saúde. A repressão ao consumo destas substâncias se associa com o objetivo de generalizar a compreensão de sucesso terapêutico como abstinência do uso. Os usuários carregam estigmas de "criminoso" e "doente," o que justifica a necessidade de afastá-los da vida em sociedade pela restrição à liberdade; com prisão, no primeiro caso, ou internação. O hospital psiquiátrico e as Comunidades Terapêuticas (CT) eram as instituições responsáveis pelo tratamento destes usuários, constituindo a chamada "indústria da loucura" que expandiu os leitos psiquiátricos durante o período de ditadura militar, entre as décadas de 60 e 80 (DELGADO, 2019).

Os avanços assistenciais e legais promovidos pela Reforma Psiquiátrica reduziram o número de internações psiquiátricas e institucionalizaram os Centro de Atenção Psicossocial (CAPS) como serviços substitutivos ao manicômio. A assistência em Saúde Mental tem por diretriz a territorialização dos dispositivos de saúde com intuito de promover cuidado articulado com a realidade sociocultural das pessoas, isto é, incluindo a comunidade. Nesta mesma lógica, a Redução de Danos se afirmou, em 2005, como política pública para os usuários de drogas com modelo de cuidado de baixa de exigência, abordando os problemas associados ao uso de forma biopsicossocial. A direção do tratamento visa dar lugar às escolhas do sujeito e considerar seu contexto social de vida. $\mathrm{O}$ foco deixa de ser ao uso de droga, mas à promoção de saúde destes usuários (TORRES; VIDAL, 2017).

Este artigo propõe a tese de haver uma relação de continuidade lógica entre as instituições de internação de usuários e as cenas de uso de drogas, comumente chamadas de cracolândias ou bocas de fumo. O objetivo geral é problematizar o risco de estas instituições se tornarem dispositivos produtores de segregação, seja pela restrição de liberdade do próprio

\section{POLÊM!CA | LABORE}

Polêmica - Revista Eletrônica da Uerj - Rua São Francisco Xavier, 524, $1^{\circ}$ andar

bloco D, sl.1001 • Tels.: +55 21 2334-4088 / 4087 • http://www.e-publicacoes.uerj.br/index.php/polemica/index

http://www.labore.uerj.br • laboreuerj@yahoo.com.br 
tratamento, seja pela redução estigmatizante da subjetividade à nomeação de dependente químico em recuperação.

Justifica-se a importância do tema pelas recentes iniciativas do poder executivo federal em restituir o lugar de centralidade do hospital psiquiátrico na Rede de Atenção Psicossocial (RAPS) (BRASIL, 2019). Percebe-se que, apesar das mudanças na assistência em Saúde Mental, a concepção da internação como principal recurso terapêutico para os usuários de drogas se manteve viva no discurso social, respaldada por interesses políticos, especialmente, pela inclusão das CT de cunho religioso na RAPS (BRASIL, 2011).

O percurso metodológico teve início na construção de casos clínicos de pacientes internados em enfermaria especializada para usuários de álcool e outras drogas, de um hospital psiquiátrico da rede pública de saúde, de um município de grande porte, da região metropolitana do Rio de Janeiro. Foi identificada nos discursos dos usuários a recorrência de situações indicativas da relação entre as cenas de uso e a internação psiquiátrica, expressas em exemplo como "estava internado na boca de fumo" ou "sai da cracolândia direto para me internar". Visou-se analisar a tese com o arcabouço teórico da psicanálise de orientação lacaniana, utilizando os conceitos de significante, objeto, gozo e a teoria dos discursos. Os discursos são modos de aparelhamento de gozo pela linguagem que resultam em diferentes tipos de laço social e a segregação é consequência da associação entre o Discurso do Mestre, o Discurso do Capitalista e o discurso da ciência (LACAN, 1969-70/2007).

Este artigo é derivado de dissertação de mestrado $^{1}$, tendo sido aprovado pelo Comitê de Ética em Saúde pela Plataforma Brasil sob o número do CAAE 35033914.7.0000.5243.

\section{O problema das drogas pela teoria lacaniana dos discursos}

A abordagem às questões sobre drogas no contemporâneo deve levar em consideração a fratura operada pela ciência no saber e as consequências decorrentes, como a transformação da droga em substância química isolada e fixada como uma fórmula. Os avanços técnicos no isolamento do princípio ativo de um elemento da natureza e na criação de novas substâncias químicas apontam para a ação da ciência em alterar o real por formalização química e matemática. $\mathrm{O}$ discurso científico apreende um saber que passa a existir por si mesmo,

1 TORRES, M. R. S. Internação de usuários de drogas: gozo e segregação na clínica das neuroses. 2015. 125 f. Dissertação (Mestrado em Psicologia) - Instituto de Psicologia, Universidade Federal Fluminense, Niterói, 2015.

\section{POLÊM!CA $\mid$ LABORE}

Polêmica - Revista Eletrônica da Uerj - Rua São Francisco Xavier, 524, $1^{\circ}$ andar

bloco D, sl.1001 • Tels.: +55 21 2334-4088 / 4087 • http://www.e-publicacoes.uerj.br/index.php/polemica/index

http://www.labore.uerj.br • laboreuerj@yahoo.com.br 
autônomo às concepções simbólicas ou culturais. Nesta medida, esvazia todos os saberes sobre as práticas de drogas, produz o sujeito como resto de sua operação e transforma a droga em novo meio de gozo. A psicanálise acolhe a experiência subjetiva excluída da ciência ao reconhecer no gozo o aspecto singular do sujeito (SANTIAGO, 2001).

A prática clínica das toxicomanias se depara com sujeito que adere à nomeação ofertada pelo Outro social como tentativa de fazer valer a homogeneização proposta pela ciência. A fórmula "eu sou dependente químico" tenta ofuscar a singularidade da experiência de ser falante sob um único significante. Contrariando a tradição da atenção aos usuários de droga que parte do pressuposto do reconhecimento do consumo como uma doença, cujo tratamento começa com a assunção da nomeação de doente, a psicanálise sustenta outra posição. Cabe ao psicanalista escutar a particularidade existente na relação do sujeito com o gozo mediado pela droga. Nas práticas institucionais de internação, o trabalho do analista é atravessado por diferentes discursos que constituem o Outro institucional.

A partir destas considerações e com intuito de embasar a discussão sobre a função da internação e a clínica possível na instituição, apresenta-se o que Lacan (1969-70/2007) teorizou como os quatro discursos, em especial, o Discurso do Mestre e sua variante, o Discurso do Capitalista. O Discurso do Mestre se enuncia a partir de um significante que representa o sujeito para outro significante. Entende-se por significante a referência ao elemento linguístico que, em si, não tem sentido, mas em relação a outros, produz o significado. A linguagem é constitutiva da experiência humana e a função da fala ultrapassa a mera comunicação, sendo um modo de produção de experiência subjetiva. É tomando este discurso como primeira referência que se obtém os outros três, sejam eles o Discurso do Universitário, o Discurso da Histérica e o Discurso do Analista, através de um quarto de giro dos elementos que o constitui, a saber, $\mathrm{S}_{1}$ (significante mestre), $\mathrm{S}_{2}$ (saber), $\$$ (sujeito dividido), a (objeto causa de desejo/dejeto).

A formulação dos quatro discursos parte dos quatro lugares fixos de agente, Outro, verdade e produção, que devem ser lidos no sentido de giro a partir do lugar de agente ao Outro. Os discursos se constituem como articulação entre o sujeito e o Outro, ordenados a partir do lugar do agente. No Discurso do Mestre, significante-mestre $S_{1}$ ocupa o lugar de agente que, endereçado ao $\mathrm{S}_{2}$ na posição do saber do Outro, induz a perda do objeto $a$. Isto significa uma perda de gozo e seu retorno como um bônus de gozo ou mais-de-gozar, por isto, pensar este

\section{POLÊM!CA | LABORE}

Polêmica - Revista Eletrônica da Uerj - Rua São Francisco Xavier, 524, $1^{\circ}$ andar

bloco D, sl.1001 • Tels.: +55 21 2334-4088 / 4087 • http://www.e-publicacoes.uerj.br/index.php/polemica/index http://www.labore.uerj.br • laboreuerj@yahoo.com.br 
lugar como produção. No lugar da verdade, o sujeito do inconsciente aparece como \$, sujeito divido pela linguagem que ignora sua própria causa pela impossibilidade de relação do sujeito com o objeto. A consequência da incidência deste discurso é o que diz respeito ao trabalho, trabalho do inconsciente. A inscrição em um discurso implica a perda de gozo para o sujeito, de modo que o trabalho do inconsciente tenta recuperar esse gozo perdido como mais-de-gozar pela repetição sintomática. Como exemplo, pode-se interpretar com este entendimento os episódios de recaída no uso de drogas. O mais-de-gozar como tentativa de recuperação de gozo é a busca por uma experiência de gozo que nunca existiu, exemplificado pela insatisfação no sintoma histérico, ou da promessa de um gozo futuro, como na impossibilidade do sintoma obsessivo (VIDAL, 2011).

A escolha de Lacan por dar início a teoria dos discursos pelo Discurso do Mestre não é aleatória. Devemos considerar o lugar importante do $\mathrm{S}_{1}$ como o que é indivisível, exterior ao próprio significante, cuja repetição carrega sempre consigo $\mathrm{S}_{2}$, na qualidade de diferença. Podese apontar a repetição desse $S_{1}$ como a tentativa da revivência da experiência de satisfação, mas o fato de não se repetir sem tornar-se outra coisa revela a impossibilidade de um gozo pleno. Desta forma, $\mathrm{S}_{1}$ intervém na bateria significante integrada já numa rede de saber. É na repetição que o gozo irrompe como limite do saber e, nesta relação, o sujeito se constitui entre dois significantes, não sendo totalmente apreendido por um saber. Ou seja,

É na juntura de um gozo - e não de qualquer um, ele sem dúvida deve permanecer
opaco -, é na juntura de um gozo privilegiado entre todos - não por ser gozo sexual,
pois o que esse gozo designa por estar na juntura é perda do gozo sexual, na fábula
freudiana da repetição, o engendramento daquilo que lhe é radical, e dá corpo a um
esquema articulado literalmente (LACAN, 1969-70/2007, p. 17).

Os avanços da ciência e as modificações que esta produziu no laço social precisam ser analisados a partir de sua articulação com o capitalismo, não apenas como tipo de sistema econômico, mas um discurso capaz de alterar a própria economia psíquica. Conforme Lacan (1968-69/2008, p. 233) indicou, “[...] o capitalismo reina porque está estreitamente ligado à ascensão da função da ciência [...]". Neste sentido, o capitalismo introduz um novo poder que permite outra apreensão do objeto, não tanto pelo valor de troca, mas pelo valor de uso. Sem esquecer de mencionar que do lado da ciência alguma coisa escapa à sua capacidade de controle (LACAN, 1966/1998).

\section{POLÊM!CA $\mid$ LABORE}

Polêmica - Revista Eletrônica da Uerj - Rua São Francisco Xavier, 524, $1^{\circ}$ andar bloco D, sl.1001 • Tels.: +55 21 2334-4088 / 4087 • http://www.e-publicacoes.uerj.br/index.php/polemica/index http://www.labore.uerj.br • laboreuerj@yahoo.com.br 
Lacan fez uma leitura inédita da obra de Marx, ao relacionar o saber como o valor da renúncia do gozo e o modo de produção capitalista, possível de ser quantificado. Este valor não se restringe apenas à renúncia implicada pelo trabalho, pois inclui também a renúncia de gozo, na produção sintomática. A ciência e o Discurso do Capitalista favorecem a apreensão do gozo como organizável, a partir do saber que, então, está sujeito à homogeneização, a começar pelo mercado de saber (LACAN, 1968-69/2008, p. 40).

O mais-de-gozar pode ser entendido como a função da renúncia ao gozo sob efeito do discurso, ou seja, é como efeito do corte do discurso que Lacan aproxima a mais-valia do maisde-gozar. A teoria marxista identifica uma disjunção entre o valor de troca da força laboral e o valor de uso, em que o excedente se transforma em lucro para o patrão, estando inacessível ao trabalhador. Este excedente é análogo à parcela de gozo perdido e irrecuperável do mais-degozar como efeito do significante e da entrada no discurso. Desde o momento em que o mercado define qualquer objeto do trabalho humano como mercadoria, esse objeto carrega em si algo de mais-valia e também a possibilidade de recuperação como mais-de-gozar. A dimensão de perda, trabalho e tentativa de recuperação desta perda, o funcionamento lógico que Marx condiciona à performance dos meios de produção capitalistas implica também em algo que não funciona, que emperra o bom andamento do sistema. Ao mesmo tempo em que Marx viu progressos nas ciências e nas indústrias, reconheceu sintomas de decadência. Nesta medida, não sem razão, Lacan credita a Marx e não a Freud a invenção do sintoma no sentido de que o sintoma é o que não anda (VIDAL, 2011). Apesar das diferenças, na homologia entre mais-de-gozar e maisvalia "[...] trata-se do mesmo tecido, na medida em que se trata do recorte de tesoura do discurso" (LACAN, 1968-69/2008, p. 44).

Assim, a tentativa de recuperação de gozo é efetuada pela injunção ao consumo a que o mercado incita. As mercadorias satisfazem parcialmente, ao mesmo tempo em que ressaltam a falta e promovem a crença de mais satisfação com novos produtos. Observa-se que o Discurso do Capitalista transforma a insatisfação constitutiva do desejo humano em uma insatisfação incentivada e comandada pelo mercado, impelida, permanentemente, à satisfação. A expansão do mercado exige o aumento da demanda para haver consumo do excesso produzido. Neste caso, é comparável ao paralelo do desenvolvimento de novas opções de medicamentos psicotrópicos pela indústria farmacêutica e a disseminação de drogas recreativas.

\section{POLÊM!CA $\mid$ LABORE}

Polêmica - Revista Eletrônica da Uerj - Rua São Francisco Xavier, 524, $1^{\circ}$ andar bloco D, sl.1001 • Tels.: +55 21 2334-4088 / 4087 • http://www.e-publicacoes.uerj.br/index.php/polemica/index http://www.labore.uerj.br • laboreuerj@yahoo.com.br 
No Discurso do Capitalista, há a inversão de alguns elementos e estabelecem-se novas relações entre eles. Assim, o objeto $a$, que antes era velado ao sujeito, agora, dirige-se a ele, enquanto $\mathrm{S}_{1}$ se dirige ao lugar de saber. O Discurso do Capitalista cria a possibilidade do objeto $a$ como mais-de-gozar demandar satisfação ao sujeito dividido sem a mediação da alteridade. A consequência é a facilidade de uma relação direta do sujeito com o gozo através de bens de consumo que se proliferam da conjunção do discurso da ciência com o Discurso do Capitalista. As drogas são elevadas à categoria de destaque, ao permitir um uso em que o sujeito consome a si mesmo. Neste mercado, "[...] é suficiente para que isto funcione muito bem, não poderia funcionar melhor, mas justamente isto funciona rápido demais, isto se consome, isso se consome pelo que isso se consome" ${ }^{2}$ (LACAN, 1972-78/2016, p. 10).

Uma definição de capitalismo trabalhada pela psicanálise refere-se a um termo que não é completamente claro e que não pode ser tomado como um fator de causa. Pode-se entendê-lo como uma ordem civilizatória em que certas atividades sociais são reguladas pelo dinheiro (BOMSEL, 2014). O dinheiro atua como o equivalente universal, que tudo pode comprar e tudo pode substituir. Agindo como um ponto de real, o dinheiro liquida simbolicamente o agente econômico, ou o sujeito. Modifica-se a relação entre consumo e utilidade, de sorte que, quanto mais se consome, mais o consumido se torna útil. A dependência seria o aumento da utilidade do produto em função do consumo. Isso vale para todos produtos inseridos no mercado, sendo a droga um, entre vários.

Partindo desta observação, deve-se questionar se o capitalismo fabrica os transtornos associados à dependência da droga. O vício é uma função de demanda com complementaridade adjacente instrumentalizada por um agente como o marketing que potencializa a relação de dependência dos usuários. Isto não se refere apenas às drogas, mas a própria posição viciante comum nas culturas contemporâneas, cheias de produtos tecnológicos e experiências (BOMSEL, 2014, p. 94).

O Discurso do Capitalista pode ser pensado como um discurso que não faz laço social por engendrar um sujeito que se relaciona com os objetos-mercadoria. Entretanto, Terral (2003) acentuou que a relação entre o discurso e o laço social acontece no ponto onde o sujeito tem de lidar com o gozo no encontro com o outro. A barreira da impossibilidade do gozo, representada

\footnotetext{
${ }^{2}$ No original: “[...] ça suffit à ce que ça marche comme sur des roulettes, ça ne peut pas marcher mieux, mais justement ça marche trop vite, ça se consomme, ça se consomme si bien que ça se consume."
}

\section{POLÊM!CA | LABORË:}

Polêmica - Revista Eletrônica da Uerj - Rua São Francisco Xavier, 524, $1^{\circ}$ andar

bloco D, sl.1001 • Tels.: +55 21 2334-4088 / 4087 • http://www.e-publicacoes.uerj.br/index.php/polemica/index http://www.labore.uerj.br • laboreuerj@yahoo.com.br 
no matema entre o lugar da verdade e o da produção, desaparece no Discurso do Capitalista e provoca um "curto-circuito" que permita o acesso ao lugar da verdade. Obtém-se um real colonizado por objetos que reduz o gozo a um corpo esvaziado de sentido. Ainda assim, o laço social e seu modo de tratamento do gozo se fazem presentes. A característica marcante deste laço social seria a segregação como resultado da homogeneização do gozo que consequentemente exila a dimensão do gozo do outro.

Entre o Discurso do Mestre e o Discurso do Capitalista há uma particularidade topológica que permite não só sua oposição lógica, mas a passagem de um a outro sem promover o rompimento (TERRAL, 2003). Esta passagem como continuidade repousaria no fato de que o gozo interditado pela lei que funda o Discurso do Mestre reaparece no Discurso do Capitalista e o constitui como tal. Destaca-se a relação de continuidade entre a internação como uma forma de tratamento institucional do gozo e a cracolândia enquanto outro tipo de tratamento de gozo, em sua faceta de exacerbação pelo consumo excessivo de drogas. Este é o principal argumento da tese defendida neste artigo por demonstrar a dupla face da segregação: a exclusão, na restrição terapêutica da liberdade, e ocupação de áreas específicas da cidade, sob a marca da miserabilidade.

As toxicomanias podem, então, ser entendidas como um modo de gozo paradoxal. Ao mesmo tempo em que o uso abusivo de drogas se coloca como uma via contra a utopia universalizante engendrada pelo Discurso do Capitalista, é também uma recusa de ingresso na lógica do gozo fálico e sua função simbólica (BARILLOT, 2016). O problema é que o gozo é “aquilo que não serve para nada" (LACAN, 1972-73/2008, p. 11). Vê-se que o modo de tratamento do gozo hoje na cena social é indissociável das consequências do laço social no capitalismo, o que quer dizer a segregação. Lacan (1967/2003) já previra que o problema da segregação não estaria restrito aos psiquiatras. Seria um problema da época, na medida que os progressos da ciência se imiscuíram em toda a estrutura social. Assim,

Os homens estão enveredando por uma época que chamamos planetária, na qual se informarão por algo que surge da destruição de uma antiga ordem social, que eu simbolizaria pelo Império, tal como sua sombra perfilou-se por muito tempo numa civilização, para ser substituída por algo bem diverso e que de modo algum tem o mesmo sentido - os imperialismos, cuja questão é a seguinte: como fazer para que as massas humanas fadas ao mesmo espaço, não apenas geográfico, mas também ocasionalmente, familiar, se mantenham separadas? (LACAN, 1967/2003, p. 360$361)$.

\section{POLÊM!CA $\mid$ LABORE}

Polêmica - Revista Eletrônica da Uerj - Rua São Francisco Xavier, 524, $1^{\circ}$ andar bloco D, sl.1001 • Tels.: +55 21 2334-4088 / 4087 • http://www.e-publicacoes.uerj.br/index.php/polemica/index http://www.labore.uerj.br • laboreuerj@yahoo.com.br 
Antes de seguir, faz-se necessário argumentar que a segregação não é criada pelo capitalismo. Askofaré (2009) propõe pensar duas declinações da segregação, como causa ou princípio e como efeito do discurso. Segundo o autor, Lacan iniciou suas indicações sobre as práticas de segregação primeiro como efeito para depois circunscrevê-la como origem de todo discurso. Para pensar a segregação como causa, Lacan retomou o mito freudiano de "Totem e Tabu" (1913/2006), para sentenciar a segregação como origem do laço de fraternidade, pois “[...] assim como o genitor não é o pai, o consanguíneo não é o irmão, dito de outro modo, a fraternidade é o feito do significante" (ASKOFARÉ, 2009, p. 347).

A tese de Freud (1913/2006) para a constituição da sociedade supõe um estado pulsional anterior, cuja satisfação era impedida pela presença real de líder mais poderoso e caprichoso que detinha para si todos os meios de gozo. A fundação da cultura e da vida humana em civilização pode ser localizada em um ato primordial, sangrento, um assassinato. O Urvater, antes de ser pai, era um ser animalesco todo poderoso que garantia para si um gozo pleno em detrimento de todos os outros membros da comunidade. Os filhos, indivíduos mais fracos, eram incapazes de ter acesso a qualquer parcela de gozo e, por isso, invejavam o pai gozoso. Uniramse e, em grupo, assassinaram o pai. O processo de constituição da função simbólica do pai primevo pode ser descrito em três etapas lógicas que estabelecem relação direta com a construção do laço social, a partir de três insígnias da figura mítica do pai primevo: governante, inimigo e morto (MALCHER; FREIRE, 2013).

A tentativa de acesso ao gozo pelo assassinato do Urvater leva a um impasse: ninguém pode assumir seu lugar, caso contrário o lugar de exceção seria novamente constituído. Este lugar deveria ser mantido vazio, e a renúncia outrora imposta pela presença concreta é imposta pelos filhos marcados pelo pai como símbolo. A lei de proibição ao gozo irrestrito é condicionada pela incidência da linguagem e do significante. O laço social se institui pela segregação do gozo pleno, que é estruturalmente impossível, mas, ao mesmo tempo, é uma possibilidade de tratamento significante do gozo, de localizá-lo fora do corpo, de acessá-lo ainda que pontualmente (LACAN, 1969-70/2007).

A origem da civilização está localizada, então, neste tempo mítico, tempo de um passado remoto e, concomitantemente, atualidade intemporal, fundada na violência da passagem ao ato. Vê-se que o ato parricida dispersa o grupo cuja consistência era provida pelo gozo do pai, inaugurando a história por instaurar o limite no saber. No decurso da história, o lugar vazio da

\section{POLÊM!CA $\mid$ LABORE}

Polêmica - Revista Eletrônica da Uerj - Rua São Francisco Xavier, 524, $1^{\circ}$ andar bloco D, sl.1001 • Tels.: +55 21 2334-4088 / 4087 • http://www.e-publicacoes.uerj.br/index.php/polemica/index http://www.labore.uerj.br • laboreuerj@yahoo.com.br 
morte do pai será suplementado por Um a mais capaz de reunir os elementos necessários para a instituição social e dar-lhes consistência (VIDAL, 2005).

$\mathrm{O}$ apelo à mestria pode explicar a manutenção da crença em soluções definitivas para o problema das drogas, com a manutenção da potência institucional. Com a ascensão do Discurso do Capitalista como o mestre contemporâneo e a incitação ao gozo, a segregação se generaliza. Estar atento a estas considerações auxilia pensar sua afirmação de que nossa época é marcada pela "[...] entrada do mundo inteiro no caminho da segregação" (LACAN, 1967/2003, p. 367). A exteriorização do objeto $a$, enquanto condição e causa do sujeito, revela as devastações provocadas pelo significante para a produção da realidade pelo sujeito e, também, sua estrutura enquanto um condensador para o gozo ao regular o prazer. Só é possível ter acesso à realidade por um enquadre produzido pela fantasia que é uma montagem em resposta à falta. Nos efeitos do Discurso do Capitalista, a fantasia parece não mais cumprir seu papel de velamento ao objeto e o sujeito está cada vez mais capturado pelo objeto $a$.

Em outra instância, interroga-se a questão da liberdade pelo viés do gozo e do impossível. A realidade é uma construção em resposta à segregação de um impossível de ser simbolizado, ou melhor, segregação do próprio gozo. Lacan (1967/2003, p. 362) ressaltara que a posição ética da psicanálise se dá em direção ao gozo pelo motivo de que "[...] toda formação humana tem, por essência, e não por acaso, de refrear o gozo". Os discursos se estruturam a partir do impossível que lhe é próprio, quer seja governar, educar, psicanalisar ou fazer desejar, a estrutura de cada discurso exige uma impotência como barreira do gozo.

No Discurso do Capitalista esse impossível, esse real, esse $a$ se transforma nos gadgets, nas latusas que Lacan define como "os pequenos objetos a que vão encontrar ao sair, no pavimento de todas as esquinas, atrás de todas as vitrines, na proliferação desses objetos feitos para causar o desejo de vocês, na medida em que agora é a ciência que os governa" (LACAN, 1969-70/2007, p. 172). A produção capitalista engendra seus objetos que visam capturar o sujeito ao oferecer-lhe objetos de gozo como causa do desejo. Com o Discurso do Capitalista como o mestre moderno, as instituições se proliferam, oferecendo-se ao sujeito como um modo de sanar as mazelas decorrentes do impossível, do real, pela ordem e o controle generalizado a tudo e todos, velando, através de seu poder, a máxima da inexistência do Outro do Outro, da disjunção do saber e verdade. No primeiro caso, tampona-se a falta com a proliferação dos objetos de gozo das compulsões mais diversas ou com a restrição a um gozo monótono das

\section{POLÊM!CA | LABORE}

Polêmica - Revista Eletrônica da Uerj - Rua São Francisco Xavier, 524, $1^{\circ}$ andar

bloco D, sl.1001 • Tels.: +55 21 2334-4088 / 4087 • http://www.e-publicacoes.uerj.br/index.php/polemica/index http://www.labore.uerj.br • laboreuerj@yahoo.com.br 
toxicomanias; no segundo, a falta é escamoteada pelo comando do mestre de que as coisas funcionem, de que os doentes se curem, de que os presos se corrijam.

A consequência prática destas considerações pode ser apontada com o que se convencionou chamar de "cenas de uso" como o contexto de ingestão de drogas por um grupo de pessoas em determinado território na cidade. Entretanto, estas cenas não se restringem à localização geográfica, tendo em vista que uma das características das cracolândias é constituirse como uma territorialidade itinerante, a mercê das intervenções dos dispositivos do Estado para a ordenação pública (RUI, 2012). Estes espaços são criados pela soma do jogo complexo de relações entre as pessoas e as representações difundidas na grande mídia (TAVARES, 2013). Uma de suas facetas pode ser tomada a partir das falas dos usuários recolhidas dos casos clínicos como um lugar de uso intenso de drogas, de um gozo restrito ao corpo a ponto de ser apenas um corpo a gozar: não se alimentam, não se hidratam, apanham, chegam a exaustão. Este lugar de segregação exprime o mais além do prazer, onde não basta o uso da droga, é preciso consumir-se neste uso, abandonar trabalho, casa e família.

As aglomerações de pessoas em situação de vulnerabilidade trazem à cena social a dimensão do deslocamento de massas de pessoas e da perda do sentimento de pertencimento à cidade ou à sociedade. A prática da droga constitui uma nomeação estigmatizante, fortemente correlacionada à periculosidade. Como afirmou uma paciente: "na rua ninguém tem nome, é só apelido". E todos aqueles que ocupam posição de alteridade se transformam em "tio" ou "tia" também sob a marca desta homogenização. Existe uma particularidade na forma como se constroem os laços entre as pessoas, nestes espaços, através das

[...] formações de redes entre consumidores e passantes da droga; a estetização desesperadora da dor e [...] o atrofiamento do sentimento ético, no sentido do aniquilamento do desejo do sujeito e da destituição do que conhecemos da formação do laço social, na medida em que se instala o império das necessidades e a aglomeração de indivíduos podem sugerir uma convivência social (CARNEIRO, 2012, p. 372).

O suporte institucional se torna um recurso, quando os circuitos de regulação de excesso e esvaziamento de gozo falham e é preciso um tempo de parada. Este também é um momento de possibilidade de encontro com o Outro a ser construído pelo lugar de fala, na medida em que possa incidir como uma pontuação pelo significante do que é só ato. Isto é o sujeito do inconsciente, que comparece quando algo falha, manca, pois o "[...] inconsciente se manifesta sempre como o que vacila num corte do sujeito" (LACAN, 1964/2008, p. 34). A instituição,

\section{POLÊM!CA $\mid$ LABORE}

Polêmica - Revista Eletrônica da Uerj - Rua São Francisco Xavier, 524, $1^{\circ}$ andar bloco D, sl.1001 • Tels.: +55 21 2334-4088 / 4087 • http://www.e-publicacoes.uerj.br/index.php/polemica/index http://www.labore.uerj.br • laboreuerj@yahoo.com.br 
nesta medida, se não orientada pela singularidade do sujeito, corre o risco de se transformar em mais um dos lugares da repetição, dessa repetição de um real que "[...] retorna sempre ao mesmo lugar - esse lugar onde o sujeito, na medida em que ele cogita, onde a res cogitans, não o encontra" (LACAN, 1964/2008, p. 54).

\section{A clínica nos lugares de segregação}

A prática psicanalítica problematiza a segregação implícita do enfoque sociológico de dar estatuto de existência autônoma ao conceito de "toxicômano." Privilegiar o diagnóstico em detrimento da experiência subjetiva reforça a homogeneização fabricada pela ciência que remete, no contemporâneo, a certos sintomas, que produz um grupo de pessoas em detrimento da singularidade do caso, justamente, a prática sustentada pela psicanálise (SCIARA, 2007). Essa homogeneização também incitada pelo Discurso do Capitalista tem como consequência produzir cada vez mais fenômenos segregativos. Se a organização das favelas e das periferias pode ser lida como decorrente das alterações nas cidades pelo capitalismo e o desenvolvimento econômico dos grandes centros urbanos (SILVA; SILVA, 2013), as cracolândias se tornam espaço de segregação na segregação. Do mesmo modo, dentre os usuários de drogas, os cracudos são segregados como o mais alto grau de degradação. Este fenômeno está intrinsecamente ligado ao processo de especialização cada vez maior nas disciplinas científicas, inclusive nas práticas de cuidado em saúde. Sciara (2007) alerta haver perigo ético em sobrevalorizar características de uma clínica de segregação por ser fácil transformá-la em uma clínica segregadora e, consequentemente, abordar estas populações como párias desumanizadas ou objetos descartáveis. Mais uma vez, as instituições de internação para usuários de drogas correm risco de reproduzir o processo histórico que transformou o hospital psiquiátrico em depósito humano comparável aos campos de concentração do holocausto nazista.

$\mathrm{Na}$ clínica, pode-se entender ainda a intoxicação crônica como uma forma de ruptura com o Outro e de recusa do inconsciente, de tal forma que a demanda pelo acolhimento institucional também cai neste lugar, se considerada ideia de que todos os toxicômanos são iguais por pertencerem a mesma comunidade de gozo. A singularidade do sujeito é escamoteada sob a homogeneização das formas de gozo operada pelo Outro social pela criação de diversas instâncias destinadas a realizar a ortopedia do gozo. Neste contexto, observa-se a proliferação de instituições cada vez mais especializadas que oferecem a cura de determinado transtorno

\section{POLÊM!CA $\mid$ LABORE}

Polêmica - Revista Eletrônica da Uerj - Rua São Francisco Xavier, 524, $1^{\circ}$ andar

bloco D, sl.1001 • Tels.: +55 21 2334-4088 / 4087 • http://www.e-publicacoes.uerj.br/index.php/polemica/index http://www.labore.uerj.br • laboreuerj@yahoo.com.br 
através da hospitalização, do isolamento, da religião, de técnicas e práticas que visam incidir sobre o sintoma ou o suposto causador do transtorno - no caso, a droga - sem considerar a experiência do sujeito e sua responsabilidade por seu gozo. Os usuários de drogas podem inicialmente aceitar um tratamento ofertado pela cultura que, com o tempo, apresenta sua ferocidade ao exclui-los da vida social (CHEIBUB, 2014).

Segue-se passagem do contexto da elaboração do Discurso do Capitalista:

\begin{abstract}
No desatino de nosso gozo, só há o Outro para situá-lo, mas na medida em que estamos separados dele. Daí as fantasias, inéditas quando não nos metíamos nisso. Deixar esse Outro entregue a seu modo de gozo, eis o que só seria possível não lhe impondo o nosso, não o tomando por subdesenvolvido. Somando-se a isso a precariedade de nosso modo, que agora só se situa a partir do mais-de-gozar e já nem sequer se enuncia de outra maneira, como esperar que se leve adiante a humanitarice de encomenda de que se revestiam nossas exações? (LACAN, 1973/2003, p. 533).
\end{abstract}

A resposta do Outro social às questões trazidas à cena pela modalidade de gozo das toxicomanias não implica a dimensão do Outro como alteridade. A pergunta a fazer neste ponto é: o que leva o sujeito a demandar este modo de tratamento? É válido atentar para um dito comum aos grupos de mútua ajuda de que, quando envolvido com drogas, são três os destinos do usuário que não atingem a abstinência: a prisão, a internação ou o caixão. Destes três destinos, a prisão e a internação se apresentam como pontos últimos antes da morte. Nas toxicomanias, a droga aparece como esse objeto que satisfaz a pulsão e, sendo o alvo o gozo, qualquer substância pode ocupar este lugar. Ao tentar romper com os constrangimentos da fala impostos pela linguagem, o sujeito utiliza a droga como uma forma de materializar um corpo feito para gozar de um modo dessexualizado. O problema reside no fato de que qualquer tentativa de aproximação deste gozo pleno e, portanto, dessexualizado, implica seguir na direção da morte. Sendo uma modalidade de gozo no real do corpo, a pulsão de morte como tendência de retorno ao estado inanimado irrompe sem nenhum anteparo. $\mathrm{O}$ recurso às drogas acarreta a busca de um gozo sem limites que se desvela mortífero (RIBEIRO; FERNANDES, 2013).

O que se pode situar como ponto de aproximação entre estas diferentes instituições totalizantes é a tendência à abolição da singularidade do sujeito. Embora estar em um hospital psiquiátrico nem sempre seja escolha livre e esclarecida do sujeito, há uma demanda tanto do sujeito quanto do social por estes lugares de segregação. Interroga-se se demanda que aí se insere não seria por um mestre, uma vez que nas instituições totais é o Discurso do Mestre que

\title{
POLÊM!CA $\mid$ LABORE
}

Polêmica - Revista Eletrônica da Uerj - Rua São Francisco Xavier, 524, $1^{\circ}$ andar bloco D, sl.1001 • Tels.: +55 21 2334-4088 / 4087 • http://www.e-publicacoes.uerj.br/index.php/polemica/index http://www.labore.uerj.br • laboreuerj@yahoo.com.br 
garante a coesão e põe tudo em funcionamento: a uniformização da imagem, a regulação dos horários, da alimentação, das atividades. Enfim, este discurso opera no "fato de que ele ordene, intervenha no sistema de saber" (LACAN, 1969-70/2007, p. 191).

\section{As possibilidades da clínica psicanalítica nos lugares de segregação}

O uso de drogas como recurso de enfrentamento do insuportável do real muitas vezes falha, o que pode levar o sujeito a demandar ajuda para encontrar outro tipo de tratamento. Se até tal momento o sujeito encontrava-se "internado na boca de fumo", há uma virada onde busca outra internação, desta vez num hospital, numa instituição. A ambiguidade empregada pelo sujeito ao significante "internação" deve ser acompanhada atentamente.

Freud (1921/2006) afirmou não haver separação entre a psicologia individual e a psicologia das massas. A entrada na vida em civilização carrega o fardo de que por mais sozinho que o sujeito esteja, nunca é sem outros, ou seja, a linguagem se impõe como Outro. Por este motivo, na constituição subjetiva, a divisão de interior e exterior não é rígida, ou melhor, ela é construída a partir da segregação de uma pequena parte inassimilável. Um ponto de inflexão entre dentro e fora, interno e externo, é característica da instância do Supereu na teoria freudiana, que tem características bem próximas do Outro lacaniano, se considerarmos que o Supereu é a lei e sua destruição:

[...] ele é a palavra mesma, o comando da lei, na medida em que dela não resta mais do que a raiz. A lei se reduz inteiramente a alguma coisa que não se pode nem mesmo exprimir, como o Tu deves, que é uma palavra privada de todos os seus sentidos. É nesse sentido que o supereu acaba por se identificar àquilo que há somente de mais devastador, de mais fascinante, nas experiências primitivas do sujeito (LACAN, 19531954/1993, p. 123).

O Supereu não se reduz à mera interiorização da autoridade dos pais ou à identificação ao ideal do eu, é antes um aspecto estrutural da condição humana em sua entrada na cultura pela linguagem. Ainda que o ideal do eu tenha uma dimensão social por promover laços de identificação entre os indivíduos através de elementos simbólicos, o Supereu atua sem conteúdo específico, exigindo o cumprimento por parte do sujeito de qualquer ideal do eu comum à época, às ideologias que lhe são comuns, num dado momento histórico. O Supereu é a instância que incita ao gozo sem necessariamente impor algum ideal, qualquer coisa lhe serve e nunca basta (LACAN, 1969-70/2007). O Supereu age, segundo Freud (1930/2010), como a instância que vigia e a voz crítica que julga o Eu em comparação com o ideal do eu. A suposição do

\section{POLÊM!CA | LABORÉ}

Polêmica - Revista Eletrônica da Uerj - Rua São Francisco Xavier, 524, $1^{\circ}$ andar

bloco D, sl.1001 • Tels.: +55 21 2334-4088 / 4087 • http://www.e-publicacoes.uerj.br/index.php/polemica/index

http://www.labore.uerj.br • laboreuerj@yahoo.com.br 
sujeito de que há no Outro o que lhe garante, possibilita o Supereu a transformar o desejo do Outro como uma ordem (LACAN, 1962-1963/2005) e, após o “[...] sujeito identificar seu desejo ao desejo do Outro, o supereu passa tanto a delatar a alienação do sujeito no Outro como a ordenar o gozo pleno" (MORAIS, 2011, p. 22).

Freud (1930/2010) descreveu o funcionamento paradoxal do Supereu como o que incita a renúncia pulsional e retira daí sua força para mais renúncia. Em outras palavras, a abdicação nunca é o suficiente: a satisfação da pulsão gera mal-estar assim como a abstinência traz a infelicidade. O resultado desta operação é a angústia, que Freud (1930/2010, p. 118) definiu como "variedade topológica" em relação ao sentimento de culpa.

A internação surge no campo social, tanto para o sujeito quanto para a sociedade, como crença em ser o único meio de tratamento possível para as toxicomanias. O que sustenta esta ideia é a fantasia de que existe um Outro absoluto e sem falhas de modo que o sujeito tenta escapar de sua falta pela via da identificação ao ideal do eu como ideal do Outro. A construção deste Outro pleno também pode ser entendida como proteção do sujeito contra o real. É nesta direção que aproximamos o enquadre institucional da internação, o Discurso do Mestre e a fantasia, apoiados na afirmação de Lacan (1970/2003, p. 445) que neste discurso “[...] é o maisde-gozar que só satisfaz o sujeito ao sustentar a realidade unicamente pela fantasia."

No momento da abstinência do uso de drogas, não é incomum encontrar um sujeito marcado pela culpa, arrependimento e autorrecriminação. Conforme a hipótese levantada, manifesta-se no discurso do sujeito a exata descrição feita por Freud sobre o Supereu, enquanto a instância que incita ao gozo proibido, ao mesmo tempo em que exige a renúncia pulsional, gerando assim um sentimento de culpa e uma "permanente infelicidade interna" (FREUD, 1930/2010, p. 99). Angústia, neste caso, também pode ser entendida como um excedente de gozo e eis o momento em que algo da ordem do desejo pode manifestar-se. Caberá ao clínico o seu manejo.

Do mal-estar na civilização à angústia temos a passagem do estrutural para o singular. A dimensão da angústia é fundamental para a fundação do sujeito em relação ao seu desejo. Se Freud remete a angústia à castração, podemos lê-la como o que é de singular do sujeito, pois é o “[...] corte nítido sem o qual a presença do significante, [...] seu sulco no real é impensável” (LACAN, 1962-63/2005, p. 88). Na internação, a angústia irrompe sob as injunções institucionais e o sujeito é convocado a responder, e o faz como resistência. Significa dizer que

\section{POLÊM!CA | LABORE}

Polêmica - Revista Eletrônica da Uerj - Rua São Francisco Xavier, 524, $1^{\circ}$ andar

bloco D, sl.1001 • Tels.: +55 21 2334-4088 / 4087 • http://www.e-publicacoes.uerj.br/index.php/polemica/index http://www.labore.uerj.br • laboreuerj@yahoo.com.br 
a experiência subjetiva opera em diferentes níveis, como forma de oposição ao comando de um mestre, até mesmo no aparente paradoxo de não querer submeter-se ao tratamento. Resistência deve ser entendida, então, como condição própria do sujeito do inconsciente: fugaz emergência entre dois significantes, inapreensível por um ou por outro. Lacan (1970/2003, p. 423) radicaliza o próprio conceito de inconsciente ao afirmá-lo como "apenas um termo metafórico para designar o saber que só se sustenta ao se apresentar como impossível, para que, a partir disso, confirme-se ser real (entende-se, discurso real)."

O que a clínica psicanalítica aponta é a via em que a experiência singular do sujeito interroga a atuação autônoma da substância química sobre o organismo, conforme creditado pela mestria do discurso científico. Isto se refere ao fato de que o organismo humano é atravessado pela linguagem. O corte promovido entre significante e objeto exclui a possibilidade de um objeto da satisfação plena ou de uma correspondência de um objeto a um instinto biologicamente inscrito e cabe a cada um estabelecer seu modo próprio de satisfação. A dimensão do desejo se abre e toma por apoio necessidades do organismo. A intenção do desejo implica em sua travessia pelo que é da cadeia significante, ou seja, sempre remetido a outro significante. Este é o argumento para afirmar que o desejo humano se constitui como desejo do Outro, de maneira que o sujeito deseja como alteridade de si mesmo. A necessidade se constitui como desejo, considerada a barreira imposta pelo significante, que transforma esta barreira em uma mensagem endereçada ao Outro (LACAN, 1957-58/1999, p. 227).

Desejo então está intimamente ligado à demanda, na medida que o endereçamento ao Outro se faz presente na travessia da cadeia significante. O caráter da demanda que se constitui com um desejo além da necessidade implica dizer que a necessidade não vai se satisfazer além da demanda. O problema das toxicomanias se localiza, portanto, no ponto onde a droga é elevada à categoria de um objeto de necessidade. Com isto, é a dimensão da demanda e do Outro que são abolidos e o sujeito é tomado por seu próprio corpo. Tal qual o corte que separa a necessidade do desejo,

[...] desejo se esboça na margem em que a demanda se rasga da necessidade: essa margem é a que a demanda, cujo apelo não pode ser incondicional se não em relação ao Outro, abre sob a forma da possível falha que a necessidade por aí introduzir, por não haver satisfação universal (o que é chamado de angústia) (LACAN, 1960/1998, p. 828).

\section{POLÊM!CA $\mid$ LABORE}

Polêmica - Revista Eletrônica da Uerj - Rua São Francisco Xavier, 524, $1^{\circ}$ andar bloco D, sl.1001 • Tels.: +55 21 2334-4088 / 4087 • http://www.e-publicacoes.uerj.br/index.php/polemica/index http://www.labore.uerj.br • laboreuerj@yahoo.com.br 
A angústia, assim, diz respeito ao sujeito e sua posição frente o Outro. A função do sujeito é, ela própria, constituída por sua subtração do Outro ao "descompletá-lo". O sujeito deve contar-se neste Outro, ao passo que desempenha função de falta. A experiência da angústia seria decorrente da falta da falta, em que a opacidade do desejo do Outro oprime e o coloca em posição de objeto deste gozo, sem condições do sujeito escapar.

\begin{abstract}
A angústia é esse corte - esse corte nítido sem o qual a presença do significante, seu funcionamento, seu sulco no real, é inapreensível; é esse corte a se abrir, e deixando aparecer o que vocês entenderão melhor agora: o inesperado, a visita, a notícia, aquilo que é tão bem exprimido pelo termo 'pressentimento'. Que não deve ser simplesmente entendido como o pressentimento de algo, mas também como o pré-sentimento, o que existe antes do nascimento de um sentimento (LACAN, 1962-63/2005 p. 88, grifo do autor).
\end{abstract}

Com a teoria dos discursos, Lacan (1970/2003, p. 445) destaca haver uma articulação entre a impossibilidade e a impotência na estrutura dos discursos, onde a impotência é definida pela barreira do gozo "[...] para diferenciar-se dele como disjunção, sempre a mesma, entre sua produção e sua verdade". Ou seja, o inconsciente é a própria barra, o que não funciona, isso que emperra. Ele ex-siste a partir do discurso como esse saber que falta, mas que, mesmo assim, continua a trabalhar em suas manifestações como o sonho. É nesta articulação ainda, que a psicanálise sustenta sua prática na função própria do corte através da interpretação em que o inconsciente atesta que, ao retirar-se, esvazia o discurso, mas confirma ser inconsciente. Para a psicanálise, não existe uma intervenção derradeira que tornará o inconsciente consciente. Pelo contrário, a produção subjetiva sempre permanece, ainda que diferente. A análise descobre a existência do avesso de seu discurso, isto é, o Discurso do Mestre, ao interpretá-lo. Esta é a condição de pensar a clínica a partir da psicanálise numa instituição total constituída pelo Discurso do Mestre, a subversão feita pelo Discurso do Analista é produzir a própria subversão do sujeito do inconsciente.

\title{
Considerações finais
}

O uso abusivo de álcool e outras drogas é efeito da articulação entre o discurso científico e o Discurso do Capitalista. A expansão da ciência e do capitalismo introduziu na sociedade produtos e incitou a necessidade de satisfação. A segregação é a consequência dos laços sociais balizados pela experiência de gozo, cada vez mais restrita ao corpo. É lícito sublinhar que a segregação é intrínseca a toda forma de organização social por haver a necessidade de fazer

\section{POLÊM!CA $\mid$ LABORE}

Polêmica - Revista Eletrônica da Uerj - Rua São Francisco Xavier, 524, $1^{\circ}$ andar bloco D, sl.1001 • Tels.: +55 21 2334-4088 / 4087 • http://www.e-publicacoes.uerj.br/index.php/polemica/index http://www.labore.uerj.br • laboreuerj@yahoo.com.br 
restrições ao gozo. O problema posto no contemporâneo é a extensão ampliada deste fenômeno. Se não mais referida à exclusão social radical dos grandes manicômios, agora encontra-se pulverizada em pequenos espaços espalhados pela cidade: cracolândias, comunidades terapêuticas, enfermarias especializadas, bocas de fumo.

A operação como Discurso do Mestre induz a modelos de tratamento que impõem um objetivo terapêutico generalizado a todos os indivíduos. No âmbito das políticas públicas, isto se traduz com a leitura de que a expectativa de um dispositivo clínico estruturado para erradicar um sintoma, tal qual a internação para os usuários de droga tendo como abstinência o sucesso terapêutico, incorre no risco de tornar-se autoritária e reforçar ainda mais o caráter segregatório.

O sintoma nunca é objetivamente erradicado. Desloca-se, transforma-se, deixa de produzir sofrimento paralisante, mas sendo correlato do inconsciente, ele persiste. A psicanálise sustenta sua prática tomando a angústia como índice do sujeito. A direção de tratamento não visa extingui-la. Pelo contrário, o analista deve orientar-se para permitir o sujeito elaborá-la. Por este motivo, o psicanalista não deve querer dirigir o sujeito, determinar previamente o objetivo do tratamento. A relação com o mestre que ordena ou com o objeto de gozo não garante ao sujeito uma vida plena, pelo contrário, o ponto de irrupção da angústia é o que insiste por parte do sujeito, seu ponto de vacilação frente ao desejo do Outro manifesto pela ação do Supereu. Sua função é sustentar o lugar do sujeito, impondo limite ao movimento totalizante de instituições, como internação psiquiátrica.

O desafio das sociedades humanas é não depender da garantia para a resolução dos impasses da vida em sociedade, muitas vezes apelando para um mestre. Este é o terreno fértil para a manutenção da crença na internação como a melhor forma possível de tratamento do uso problemático de drogas. Quando o sujeito é acompanhado em seu contexto social e territorial, essas transformações tornam-se potentes na produção de laço social, conforme a clínica exercida nos CAPSad demonstra. Por este motivo, a reatualização das instituições de internação recentemente adotadas a nível federal pela reintrodução dos leitos psiquiátricos como centralidade da rede de saúde mental tende a produzir mais segregação.

\section{Referências}

ASKOFARÉ, S. Aspectos da segregação. A peste, São Paulo, v. 1, n. 2, p. 345-354, jul./dez. 2009. Disponível em: https://revistas.pucsp.br/apeste/article/view/6287. Acesso em: 01 abr. 2015.

\section{POLÊM!CA $\mid$ LABORE}

Polêmica - Revista Eletrônica da Uerj - Rua São Francisco Xavier, 524, $1^{\circ}$ andar bloco D, sl.1001 • Tels.: +55 21 2334-4088 / 4087 • http://www.e-publicacoes.uerj.br/index.php/polemica/index http://www.labore.uerj.br • laboreuerj@yahoo.com.br 
BARILLOT, P. Sair do discurso capitalista? Stylus, Rio de Janeiro, n. 33, p. 153-161, nov. 2016. Disponível em: http://pepsic.bvsalud.org/scielo.php?script=sci_arttext\&pid=S1676-157X2016000200012\&lng=pt\&nrm=iso. Acesso em: 10 jan. 2020.

BOMSEL, O. Le capitalisme engendre-t-il des addictions? La cause du desir revue de psychanalyse, Paris, $n$. 88, p. 89-94, 2014. Disponível em: https://doi.org/10.3917/lcdd.088.0089. Acesso em: 15 jan. 2015.

BRASIL. Ministério da Saúde. Portaria n 3.088 de 23 de dezembro de 2011. Institui a Rede de Atenção Psicossocial para pessoas com sofrimento ou transtorno mental e com necessidades decorrentes do uso de crack, álcool e outras drogas, no âmbito do Sistema Único de Saúde. Diário Oficial da União, Brasília, DF, n. 409, 30 de dez. 2011. Seção 1, p. 59. Disponível em: https://www.jusbrasil.com.br/diarios/33395118/dou-secao-1-30-122011-pg-59. Acesso em: 20 dez. 2019.

BRASIL. Ministério da Saúde. Coordenação-Geral de Saúde Mental, Álcool e Outras Drogas. Nota Técnica n 11/2019 de 04 de fevereiro de 2019. Esclarecimentos sobre as mudanças na Política Nacional de Saúde Mental e nas Diretrizes na Política Nacional sobre Drogas. Brasília: Ministério da Saúde, 2019. Disponível em: http://mds.gov.br/obid/nova-politica-nacional-de-saude-mental. Acesso em: 30 abr. 2020.

CARNEIRO, H. F. Cracolândia: hiper-realidade social, droga e igualdade. Polêm!ca. Rio de Janeiro, v. 11, n. 3, p. 371-384, jul./set. 2012. Disponível em: https://www.e-

publicacoes.uerj.br/index.php/polemica/article/view/3728/2610. Acesso em: 30 mar. 2015.

CHEIBUB, W. O tratamento do mal-estar na cultura: toxicomania e segregação. 2014. 117 f. Dissertação (Mestrado em Psicanálise) - Instituto de Psicologia, Universidade do Estado do Rio de Janeiro, 2014.

DELGADO, P. G. Reforma psiquiátrica: estratégias para resistir ao desmonte. Trab. educ. saúde, Rio de Janeiro, v. 17, n. 2., p. 1-4, jun. 2019. Editorial. Disponível em: https://www.scielo.br/scielo.php?script=sci_arttext\&pid=S1981-77462019000200200\&lng=e. Acesso em: 02 fev. 2020 .

FREUD, S. (1913). Totem e Tabu. In: FREUD, S. Edição standard brasileira das obras psicológicas completas de Sigmund Freud. Rio de Janeiro: Imago, 2006. V. XIII. p. 21-163.

FREUD, S. (1921). Psicologia das massas e análise do ego. In: FREUD, S. Edição standard brasileira das obras psicológicas completas de Sigmund Freud. Rio de Janeiro: Editora Imago, 2006. V. XVIII. p. 79-145.

FREUD, S. (1930). O mal-estar na civilização. In: FREUD, S. O mal-estar na civilização, novas conferências introdutórias à psicanálise e outros textos (1930-1936). São Paulo: Companhia das Letras, 2010. p. 13-321.

LACAN, J. (1953-1954). O Seminário, livro 1: os escritos técnicos de Freud. Rio de Janeiro: Jorge Zahar Editor, 1993.

LACAN, J. (1957-58). O Seminário, livro 5: as formações do inconsciente. Rio de Janeiro: Jorge Zahar Editor, 1999.

LACAN, J. (1960). Subversão do sujeito e dialética do desejo no inconsciente freudiano. In: LACAN, J. Escritos. Rio de Janeiro: Jorge Zahar Editor, 1998.

LACAN, J. (1962-1963). O Seminário, livro 10: a angústia. Rio de Janeiro: Jorge Zahar Editor, 2005.

LACAN, J. (1964). O Seminário, livro 11: os quatro conceitos fundamentais da psicanálise. Rio de Janeiro: Jorge Zahar Editor, 2008.

LACAN, J. (1966). A Ciência e a Verdade. In: LACAN, J. Escritos. Rio de Janeiro: Jorge Zahar Editor, 1998.

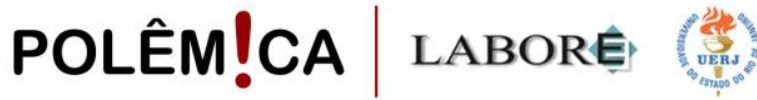

Polêmica - Revista Eletrônica da Uerj - Rua São Francisco Xavier, 524, $1^{\circ}$ andar bloco D, sl.1001 • Tels.: +55 21 2334-4088 / 4087 • http://www.e-publicacoes.uerj.br/index.php/polemica/index http://www.labore.uerj.br • laboreuerj@yahoo.com.br 
LACAN, J. (1967). Alocução sobre a criança. In: LACAN, J. Outros escritos. Rio de Janeiro: Jorge Zahar Editor, 2003.

LACAN, J. (1968-1969). O Seminário, livro 16: de um Outro ao outro. Rio de Janeiro: Jorge Zahar Editor, 2008 .

LACAN, J. (1969-1970). O Seminário, livro 17: o avesso da psicanálise. Rio de Janeiro: Jorge Zahar Editor, 2007.

LACAN, J. (1970). Radiofonia. In: LACAN, J. Outros escritos. Rio de Janeiro: Jorge Zahar Editor, 2003. p. 400-448.

LACAN, J. (1972). Du discours psychanalytique - conférence à l'université de Milan. Lacan in Italia, Milan, p. 32-55, 1978. École lacanienne de psychanalyse, 2016. Disponível em: http://ecole-lacanienne.net/wpcontent/uploads/2016/04/1972-05-12.pdf. Acesso em: 26 out. 2020.

LACAN, J. (1972-1973). O Seminário, livro 20: mais, ainda. Rio de Janeiro: Jorge Zahar Editor, 2008.

LACAN, J. (1973). Televisão. In: LACAN, J. Outros escritos. Rio de Janeiro, Jorge Zahar Editor, 2003. p. 508543.

MALCHER, F.; FREIRE, A. B. Laço social na psicose: impasses e possibilidades. Ágora, Rio de Janeiro, v. 16, n. 1, p. 119-133, jan./jun. 2013. Disponível em: http://www.scielo.br/scielo.php?script=sci_arttext\&pid=S151614982013000100008\&lng=en\&nrm=iso. Acesso em: 17 abr. 2014.

MORAIS, A. P. S. B. O supereu como estrutural do sujeito e o consumo como ideal do Outro na contemporaneidade. A peste, São Paulo, v. 3 n. 1, p. 17-36, jan./jun. 2011. Disponível em: http://revistas.pucsp.br/index.php/apeste/article/viewFile/22078/16195. Acesso em: 05 fev. 2015.

RIBEIRO, C. T.; FERNANDES, A. H. Tratamentos para usuários de drogas: possibilidades, desafios e limites da articulação entre as propostas da redução de danos e da psicanálise. Analytica, São João del Rei, v. 2, n. 2, p. 3358, jun. 2013. Disponível em: http://pepsic.bvsalud.org/scielo.php?script=sci_arttext\&pid=S231651972013000100003\&lng=pt\&nrm=iso. Acesso em: 25 mar. 2015.

RUI, T. "Isso não é um cachimbo": sobre usuários de crack, seus artefatos e suas relações. Àskesis, v. 1, n. 1, p. 32-45, jan./jul. 2012. Disponível em: http://www.marcoaureliosc.com.br/06rui1.pdf. Acesso em: 13 fev. 2015.

SANTIAGO, J. A droga do toxicômano: uma parceria cínica na era da ciência. Rio de Janeiro: Jorge Zahar Ed., 2001.

SCIARA, L. Les lieux de ségrégation constituent-ils la pointe avanceé de la clinique contemporaine? Journal Française de Psychiatrie, v. 28, n. 1, p. 35-38, 2007. Disponível em: www.cairn.info/revue-journal-francais-depsychiatrie-2007-1-page-35.htm. Acesso em: 20 nov. 2014.

SILVA, F. M.; SILVA, K. R. S. O novo modelo de segurança pública no Rio de Janeiro: violação ou garantia de direitos humanos nas favelas cariocas? Revista brasiliense de pós-graduação em ciências sociais, Brasília, $\mathrm{n}$. 11, mar. 2013. Disponível em: https://periodicos.unb.br/index.php/revistapos/article/view/19573. Acesso em: 11 ago. 2014.

TAVARES, F. R. Territorializações precárias na cidade: um estudo de caso sobre as cracolândias. História, natureza e espaço, Rio de Janeiro, v. 2 n. 2, p. 1-20, 2013. DOI: http://dx.doi.org/10.12957/hne.2013.12119.

TERRAL, F. Sur le lien social capitaliste. L'en-je lacanien, v. 1, n. 1, p. 139-150, 2003. Disponível em: http://www.cairn.info/revue-1-en-je-lacanien-2003-1-page-139.htm. Acesso em: 14 nov. 2014.

\section{POLÊM!CA $\mid$ LABORE}

Polêmica - Revista Eletrônica da Uerj - Rua São Francisco Xavier, 524, $1^{\circ}$ andar bloco D, sl.1001 • Tels.: +55 21 2334-4088 / 4087 • http://www.e-publicacoes.uerj.br/index.php/polemica/index http://www.labore.uerj.br • laboreuerj@yahoo.com.br 
TORRES, M. R.; VIDAL, P. Redução de Danos e Psicanálise de orientação Lacaniana nas internações de usuários de drogas. ECOS, Niterói, v. 7, n. 1, p. 59-67, 2017. Disponível em:

http://www.periodicoshumanas.uff.br/ecos/article/view/1835. Acesso em: 15 jan. 2020.

VIDAL, P. Freud e a nostalgia do pai. In: BERNARDES, A. (Org.). 10xFreud. Rio de Janeiro: Azougue, 2005.

VIDAL, P. Marx não sem Lacan. In: MARIANI, B. (Org.). Discurso, Arquivo e... Rio de Janeiro: Ed. Sete Letras, 2011. p. 227-234.

Recebido em: 01/04/2020.

Aceito em: 30/04/2020.

\section{POLÊM!CA | LABORE}

Polêmica - Revista Eletrônica da Uerj - Rua São Francisco Xavier, 524, $1^{\circ}$ andar bloco D, sl.1001 • Tels.: +55 21 2334-4088 / 4087 • http://www.e-publicacoes.uerj.br/index.php/polemica/index http://www.labore.uerj.br • laboreuerj@yahoo.com.br 